
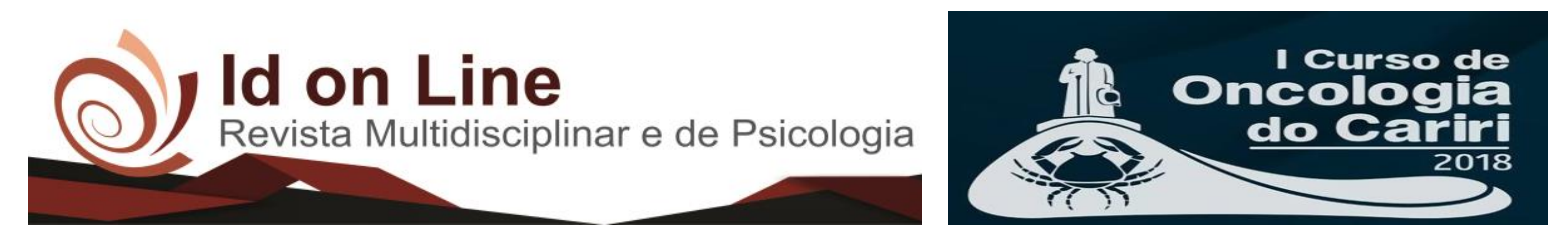

Resumo

\title{
TABAGISMO E CÂNCER: PREVENIR RISCOS OU TRATAR SEQUELAS?
}

\author{
Ana Laís Lacerda Rulim ${ }^{1}$, Marco Antônio Bezerra Rulim², Gabriel Pinheiro Machado ${ }^{\text {, }}$ \\ Ana Beatriz de Melo Alves ${ }^{1}$, Albérico Macedo Bertinode Sá Rodrigues ${ }^{1}$, Camila Nayele Viana de Oliveira ${ }^{1}$
}

Introdução: é de conhecimento quase global que o tabagismo traz ônus à saúde dos seus usuários, constituindo-se como fator de risco para inúmeras doenças, dentre elas o carcinoma espinocelular (CEC), que representa $90-95 \%$ dos casos de câncer na cavidade oral ${ }^{1}$. Objetivo: o objetivo deste artigo foi descrever o caso clínico de uma paciente idosa, tabagista de longa data, com CEC de área retromolar e história familiar positiva para a mesma neoplasia em irmã, promovendo com isso uma reflexão sobre a necessidade de prevenção contra o tabagismo. Relato de caso: paciente do sexo feminino, 64 anos, tabagista por 50 anos, procedente de Juazeiro do Norte - Ce, com história de massa cervical direita e presença de lesão em mucosa retromolar ipsilateral. Procedeu-se a investigação com realização de ultrassonografia cervical que evidenciou presença de nódulo hipoecoico medindo $3.7 \times 2.3 \mathrm{~cm}$ de localização periparotídea, confirmado por posterior tomografia computadorizada de pescoço. Seguiu-se a investigação com biópsia de lesão em mucosa retromolar direita, que concluiu tratar-se da presença de um carcinoma epidermóide espinocelular moderadamente diferenciado de grandes células, não ceratinizante e invasor. A paciente já apresentava história familiar positiva para a mesma neoplasia, em irmã. A conduta tomada foi a de excisar cirurgicamente a tumoração mediante pelveglossomandibulectomia à direita ampliada a faringe+ esvaziamento cervical radical ampliado à direita + reconstrução com retalho de peitoral maior. A paciente evoluiu bem, estável, sem quaisquer intercorrências no pós operatório. Conclusão: o caso em questão fornece uma reflexão sobre a importância da profilaxia primária de doenças que têm como fator de risco o tabagismo. Nas entrelinhas de uma história clínica de uma paciente com CEC de cavidade oral, exposta por longos períodos ao tabaco, torna-se notável o potencial que uma intervenção precoce contra o tabagismo teria de prevenir danos, e, no caso em questão, prevenir duplamente, pois tanto a paciente supracitada como a irmã foram acometidas pelo mesmo tipo de câncer. A partir desta análise, portanto, pode-se perfeitamente afirmar ue a frase "prevenir é melhor do que remediar" torna-se não só um dito popular, mas um axioma para o exercício responsável da medicina.

Palavras-Chave: carcinoma epidermóide; neoplasia bucal; tabagismo; prevenção.

\footnotetext{
${ }^{1}$ Acadêmico de Medicina da Faculdade de Medicina (FMJ) de Juazeiro do Norte / CE;

${ }^{2}$ Médico cirurgião geral pelo Hospital Universitário Alcides Carneiro (UFCG) e professor auxiliar da disciplina Clínica Cirúrgica II da Faculdade Estácio Medicina de Juazeiro do Norte - CE;

Autor correspondente: Email: analaislacerda@gmail.com.
} 